\title{
Pavement performance and application of anion rubber-modified asphalt
}

\author{
HONG Wei ${ }^{1}$, LI QingShan ${ }^{1 *}$, GUAN GuoQuan ${ }^{2}$, LIU Jun $^{1}$, SUN Jing $^{3}$ \& XING GuangZhong ${ }^{1}$ \\ ${ }^{1}$ State Key Laboratory of Metastable Materials Science and Technology, Yanshan University, Qinhuangdao 066004, China; \\ ${ }^{2}$ Hesen Chemical Technology Co., Ltd., Chengdu 610072, China; \\ ${ }^{3}$ English Department, Foreign Languages College, Yanshan University, Qinhuangdao 066004, China
}

Received May 16, 2011; accepted November 22, 2011; published online April 12, 2012

\begin{abstract}
We have used a unique process to develop the first successful anion rubber modified asphalt mixture. Rubber and asphalt are used in equal proportions in the mix. Compared with conventional asphalt, the anion rubber modified asphalt show better pavement performance, and fully met the relevant specifications. The dynamic stability and failure strain indicators are better than those of SBS modified asphalt. Compared with traditional rubber modified asphalt, the amount of waste tires incorporated into this new rubber modified asphalt is much greater; the new asphalt also improved the air quality near the road, thus providing great economic and social benefits.
\end{abstract}

waste tire rubber, asphalt mixture, dynamic stability, anions, environmental protection

Citation: Hong W, Li Q S, Quan G Q, et al. Pavement performance and application of anion rubber-modified asphalt. Chin Sci Bull, 2012, 57: 2323-2328, doi: $10.1007 / \mathrm{s} 11434-012-5065-7$

With the rapid development of the Chinese auto industry and increasing quality of life, car ownership is increasing and we are facing the problem of dealing with many waste tires. The statistics show that the total amount of waste tire in China in 2011 is 2.5278 million tons, and by 2012, it is expected to reach 2.8451 million tons [1]. Such a huge amount represents a heavy social and environmental burden.

The main measures for dealing with this problem at present include stacking (or tamping), burning and recycling. The application of crumb rubber in road construction has become a focus of research and development globally; it is also one of the best choices for dealing with huge numbers of waste tires $[2,3]$.

\section{Anion rubber-modified asphalt}

\subsection{Main materials}

100\# matrix asphalt was obtained from Asphalt Company,

*Corresponding author (email: qsli@ysu.edu.cn)
Shengli oilfield, Dongying City, Shandong Province. Recycled rubber powder, 20-100 $\mu \mathrm{m}$ diameter was obtained from Fangdahuanyu Co, Ltd. Dongguan. Anion additive: 15-400 nm diameter was obtained from Yanda Qicai Technology Limited Company. Cross-linking agent were self-prepared.

\subsection{Preparation of anion rubber-modified asphalt}

The matrix asphalt was prepared to the liquation stage, and the rubber powder was dehydrated. The two were combined in an appropriate ratio (we used a high proportion modified adulteration technique, so the proportion of rubber to asphalt can reach up to $1: 1$ ), and churned until well mixed, followed by heating up to $180^{\circ} \mathrm{C}$. The mixture was then homogenized for $30 \mathrm{~min}$ at a temperature of $170-190^{\circ} \mathrm{C}$ and a speed of 4000-6000 r/min using a high shear scattered emulsifying machine. Then the required amount of anion additive was added, followed by blending for a further 30 min. The mixture was cooled to $160 \pm 10^{\circ} \mathrm{C}$, and stood for 30 min to give the anion rubber-modified asphalt. 


\subsection{Fourier Transform infrared spectroscopy (FTIR)}

Figure 1 shows the FTIR spectra of the anion additive, rubber modified asphalt and anion rubber modified asphalt. The characteristic peak at $3425 \mathrm{~cm}^{-1}$ is the stretching vibration absorption band for $\mathrm{O}-\mathrm{H}$, and depends upon the $\mathrm{H}-\mathrm{OH}$ angle. The two peaks characteristic of the anion additive appear strongly in the spectrum of anion rubber modified asphalt, and are absent in that of rubber modified asphalt. This indicates that the anion additive exists stably in the anion rubber modified asphalt. No new peaks emerged $[4,5]$.

The above analysis indicates addition of anion additive into rubber-modified asphalt is a physical admixing process. There are only Van der Waals forces between the components, and new functional groups are not generated. In addition, because the particle diameter of the anion additive is at the nano level, the miscible system is uniform and stable, and thus suitable for production.

\section{Anion Rubber modified asphalt performance testing}

\subsection{Test items, standards and equipment}

Testing of the asphalt, including designing the proportions of the mixture, evaluating its properties and evaluating its road capability was carried out in accordance with "Standard Test Methods of Bitumen and Bituminous Mixtures for Highway Engineering" (JTJ052-2000) and "Technical Specifications for Construction of Highway Asphalt Pavements" (JTG F40-2004). We then evaluated the anion release performance [6-8]. The equipment used in the experiments is given in Table 1 .

\subsection{Anion rubber modified asphalt mixture ratio design}

(1) Grading of mineral aggregate. In this experiment the mineral aggregate gradation type is $\mathrm{AC} 13$, as shown in

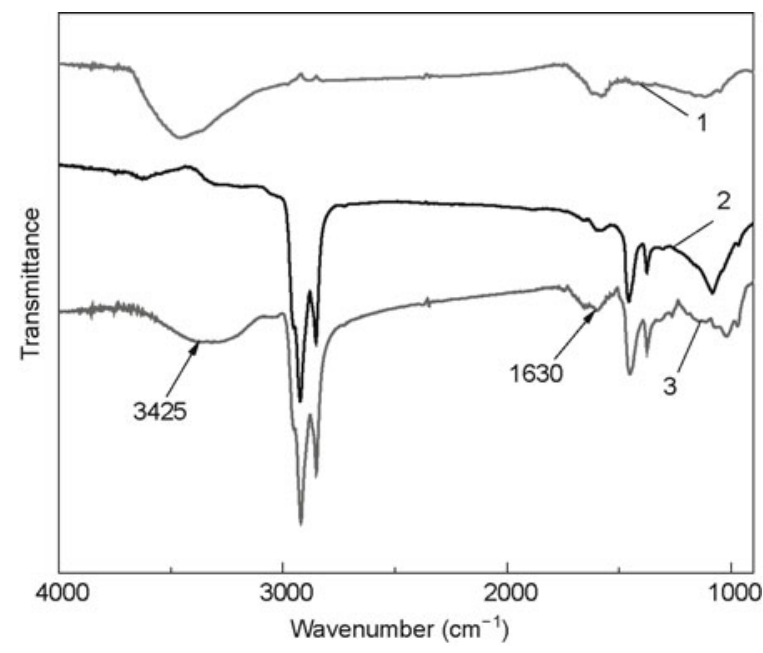

Figure 1 The FTIR spectra of anion additives, rubber modified asphalt and anion rubber modified asphalt. 1, Anion additives; 2, rubber modified asphalt; 3, anion rubber modified asphalt.

Table 2.

(2) Marshall compaction test of anion rubber modified asphalt mixture. This test uses the standard Marshall compaction method (T0702-2000) to determine the asphaltaggregate ratio of the asphalt mixture. The sample is compacted 75 times on two faces at a compaction temperature of $165^{\circ} \mathrm{C}$. The gross volume of asphalt mixture is determined using the "wax seal method", and the theoretical maximum density (dry density) is determined using the "vacuum law". The paraffin density is $0.87 \mathrm{~g} / \mathrm{cm}^{3}$, and the test water temperature is $20^{\circ} \mathrm{C}$.

Anion rubber modified asphalt mixture Marshall compaction test results and compaction curves are shown in Table 3 and Figure 2.

(3) Determining the optimum asphalt-aggregate ratio for anion rubber modified asphalt mixture. To determine the best asphalt-aggregate ratio for anion rubber modified asphalt mixture, a comprehensive analysis was performed to find the asphalt-aggregate ratio corresponding to maximum density, minimum VMA (voids in mineral aggregate) and

Table 1 Main Instruments and Equipment

\begin{tabular}{clll}
\hline Serial No. & Equipment name & Equipment model & Instrument manufacturer \\
\hline 1 & Electric blast oven & XMTA & Shanghai Biaocheng Labroratory \\
2 & Rut forming apparatus & HYCX-1 & Zhongdeweiye Equipment Co., Ltd. \\
3 & Rutting test machine & HYCZ-5 & Cangzhou Zhongjian Precision Instrument Co., Ltd. \\
4 & Electronic universal testing machine & WDW1020 & Instron Co., USA \\
5 & Air ion detector & DLY-6A232 & Lianteng Electronic Co., Ltd. Zhangzhou, Fujian \\
\hline
\end{tabular}

Table 2 AC13 Gradation

\begin{tabular}{lrrrrrrrrrrr}
\hline Sieve mesh $(\mathrm{mm})$ & 16 & 13.2 & 9.5 & 4.75 & 2.36 & 1.18 & 0.6 & 0.3 & 0.15 & 0.075 \\
\hline Cumulative pass rate $(\%)$ & 100 & 97.5 & 66.7 & 30 & 23.5 & 18.4 & 14.5 & 11.4 & 8.9 & 7 & \\
\hline
\end{tabular}


Table 3 Marshall compaction test results for anion rubber modified asphalt mixture

\begin{tabular}{ccccccc}
\hline Asphalt-aggregate ratio & Bulk density $\left(\mathrm{g} / \mathrm{cm}^{3}\right)$ & Percent of void $(\%)$ & Dry density $\left(\mathrm{g} / \mathrm{cm}^{3}\right)$ & VMA $(\%)$ & VCA $(\%)$ & VFA $(\%)$ \\
\hline 5.6 & 2.4533 & 5.94 & 2.3232 & 15.38 & 4.087 & 61.39 \\
6.0 & 2.4670 & 4.84 & 2.3273 & 15.23 & 40.76 & 68.25 \\
6.4 & 2.4825 & 3.83 & 2.3332 & 15.02 & 40.61 & 74.51 \\
6.8 & 2.4872 & 2.96 & 2.3289 & 15.18 & 40.72 & 80.51 \\
7.2 & 2.4884 & 2.42 & 2.3212 & 15.46 & 40.92 & 84.37 \\
\hline
\end{tabular}
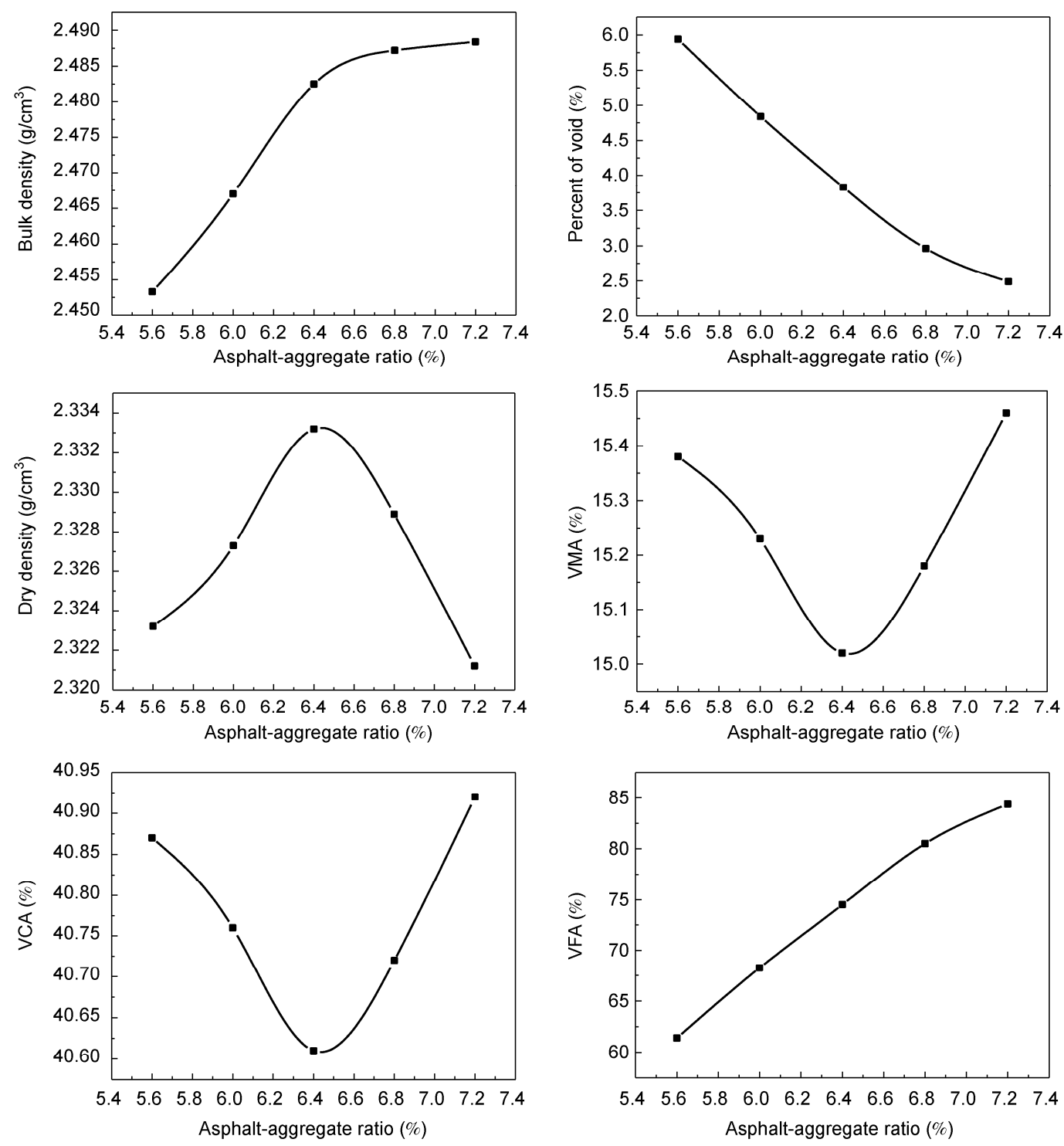

Figure 2 Marshall test curves for anion rubber modified asphalt mixture.

VCA (percent air voids in coarse aggregate).

Asphalt-aggregate ratio corresponding to the maximum dry density: $\mathrm{OAC}_{1}=6.38 \%$;

Asphalt-aggregate ratio corresponding to the minimum VMA: $\mathrm{OAC}_{2}=6.38 \%$;

Asphalt-aggregate ratio corresponding to the minimum VCA: $\mathrm{OAC}_{3}=6.38 \%$;

Optimum asphalt-aggregate ratio of anion rubber modi- fied asphalt mixture: $6.38 \%$.

\subsection{Evaluation of anion rubber modified asphalt pavement performance}

Evaluation of anion rubber modified asphalt pavement performance was performed under the optimum asphaltaggregate ratio conditions [9-12]. 
(1) High-temperature rutting test. Under the requirements of "Highway engineering asphalt and asphalt testing procedures" (JTJ052-2000), the wheel grinding method was used in making track plate specimens with the size of $300 \mathrm{~mm} \times 300 \mathrm{~mm} \times 50 \mathrm{~mm}$, after which process their dynamic stability were determined. The test results are in Table 4 .

Dynamic stability is an indicator which reflects the resistance of the asphalt mixture to permanent deformation at high temperature, and is more intuitive than the Marshall Stability Index. The higher the asphalt mixture dynamic stability, the stronger its rutting resistance and the better its stability at high temperature.

Table 4 shows that anion rubber modified asphalt mixture has a dynamic stability (9533.3 times $/ \mathrm{mm}$ ) much higher than that specified in the "Technical Specification for Construction of Asphalt Pavement" (JTG F40-2004) ( $\geqslant 2800$ times/mm), and also higher than that of SBS modified asphalt (about 4500 times $/ \mathrm{mm}$ ). This is largely because the rubber particles can still maintain a high elastic deformation at high temperature $\left(60^{\circ} \mathrm{C}\right)$ and therefore show strong recovery. From the mechanical viewpoint, compression of the rubber particles generates an internal rebound stress; in effect, the asphalt part of the mixture experiences a smaller overall stress, thus improving its ability to resist external forces.

(2) Low temperature trabecular bending test. The low temperature trabecular bending test can be used to evaluate the low temperature crack resistance of asphalt mixtures. The tests were carried out in accordance with the "Highway engineering asphalt and asphalt testing procedures" (JTJ052-2000), using a WDW1020 electronic universal testing machine (Beijing Office of Instron Co., Ltd., Su park 60921 room, Beijing Friendship Hotel, Haidian District, Beijing) at a temperature of $-10^{\circ} \mathrm{C}$ and loading rate of $1 \mathrm{~mm} / \mathrm{min}$. The low temperature damage stiffness modulus is an indicator of the crack resistance of the asphalt mixture at low temperature. The higher the lower temperature damage stiffness modulus of the asphalt mixtures, the better low temperature cracking resistance they have. The result is shown in Table 5.

The anion rubber modified asphalt mixture failure strain $(7845.9 \mu \varepsilon)$ is much higher than that required by the "Technical Specification for Construction of Asphalt Pavement" (JTG F40-2004), ( $\geqslant 2800 \mu \varepsilon)$ and is also higher than that of SBS modified asphalt (around $3000 \mu \varepsilon$ ). This is mostly because of the high waste rubber content in the anion rubber modified asphalt mixture which provides good low temperature flexibility.

(3) Water stability test. The water stability test evaluates the resistance to water damage of the anion rubber modified asphalt mixture. The parameter determined is the freezethaw splitting intensity ratio (TSR), which is the ratio of splitting tensile strength of the mixture before and after freezing and thawing. Larger values of TSR correspond to better water stability of the asphalt mixture. The test results are shown in Table 6.

The TSR of the anion rubber modified asphalt mixture meets the requirements of the "Technical Specification for Construction of Asphalt Pavement" (JTG F40-2004), and thus the mixture shows satisfactory water stability.

\subsection{Anion release performance evaluation of the anion rubber modified asphalt}

(1) Testing. Using the DLY-6A232 Air Ion Detector (Lianteng Electronic Co., Ltd. Jinling Branch Road No. 1, Jinfeng Development Zone, Zhangzhou City, Fujian Province, China), the anion release behavior of a natural anion asphalt pavement (i.e. paved with anion rubber modified asphalt) was tested. The test results were compared with the laboratory test results and test results from the literature to enable conclusions to be drawn [13]. Test results are shown in Figures 3-5 and Table 7.

The air anion concentration of the road asphalt containing the admixed anion additive is about 3000 anions $/ \mathrm{cm}^{3}$ without sunshine and about 5000-6000 anions $/ \mathrm{cm}^{3}$ in the sunshine. When vehicles pass by, there is a noticeable change in the concentration. The air anion concentration average of other road is $100-200$ anions $/ \mathrm{cm}^{3}$.

Table 4 Dynamic stability test

\begin{tabular}{ccc}
\hline Test items & Dynamic stability (times $/ \mathrm{mm})$ & Technical requirements in construction specification (times $/ \mathrm{mm})$ \\
\hline Rutting test & 9533.3 & $\geqslant 2800$ \\
\hline
\end{tabular}

Table 5 Bending strain test

\begin{tabular}{lcc}
\hline Test items & Failure strain $(\mu \varepsilon)$ & Technical requirements in construction specification $(\mu \varepsilon)$ \\
\hline Low temperature bending test & 7845.9 & $\geqslant 2800$ \\
\hline
\end{tabular}

Table 6 Water stability test

\begin{tabular}{ccc}
\hline Standard condition splitting intensity (MPa) & Freeze-thaw splitting intensity (MPa) & TSR (\%) \\
\hline 0.274 & 55.9 \\
\hline
\end{tabular}



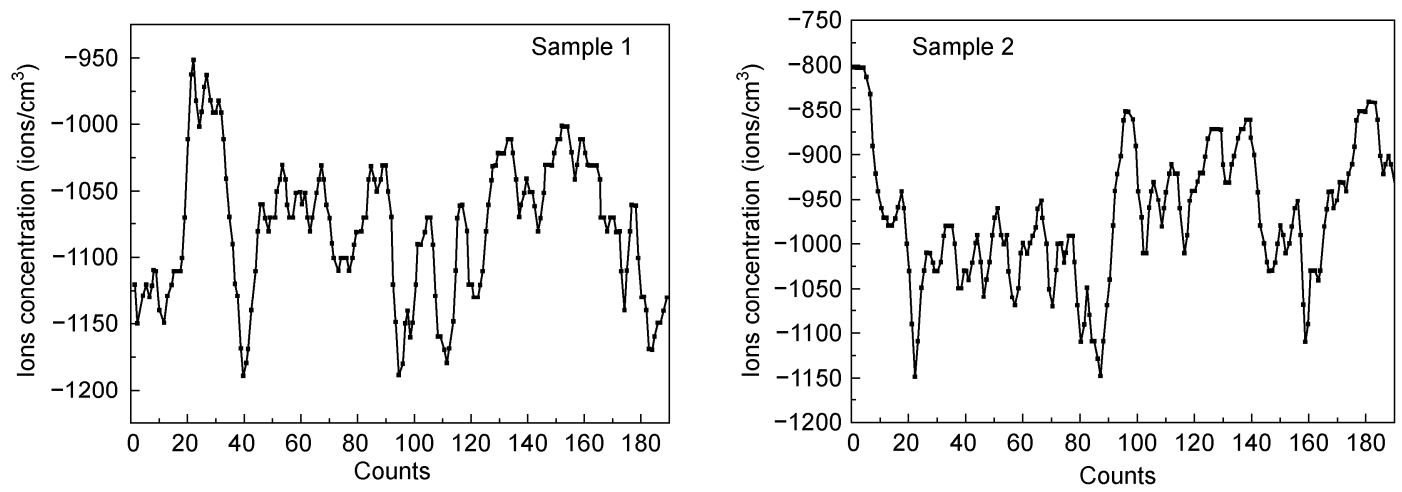

Figure 3 Anion release test in laboratory.
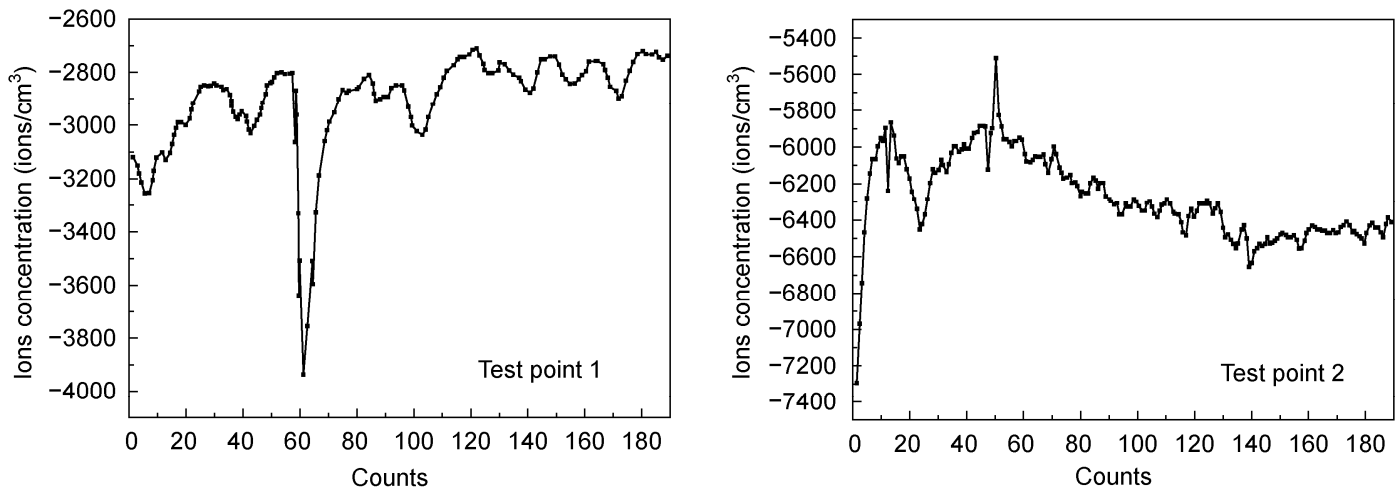

Figure 4 Natural anion asphalt pavement anion release test.
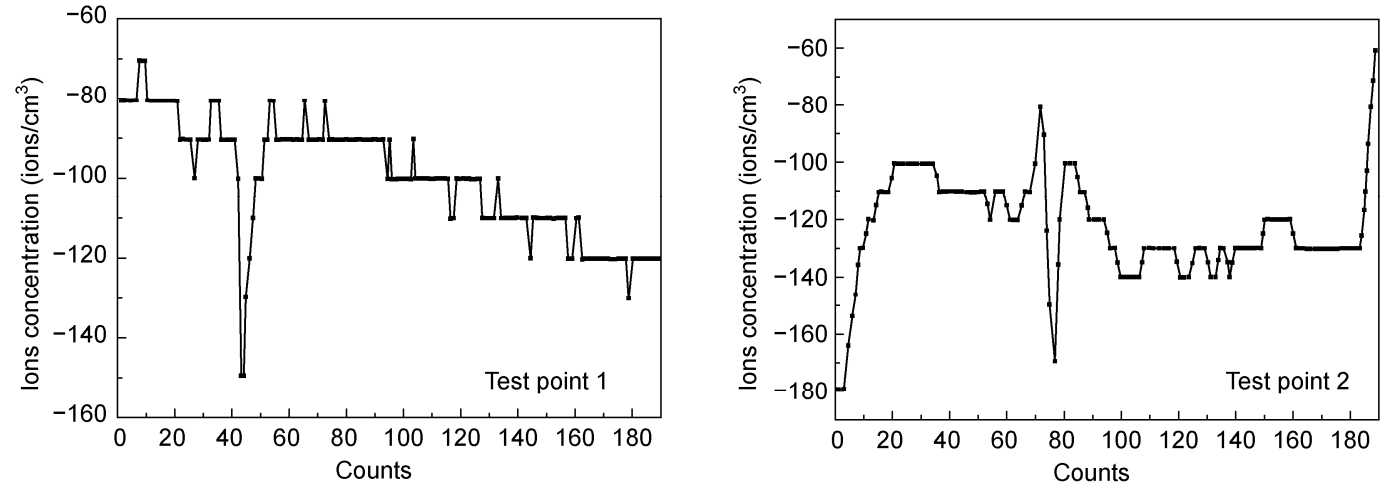

Figure 5 Common road asphalt pavement anion release test.

Table 7 Anion release test results for laboratory samples and asphalt pavement

\begin{tabular}{|c|c|c|c|c|c|c|}
\hline Test location & & $\begin{array}{c}\text { Maximum anion } \\
\text { concentration } \\
\left(\text { anions } / \mathrm{cm}^{3}\right)\end{array}$ & $\begin{array}{l}\text { Minimum anion } \\
\text { concentration } \\
\left(\text { anions } / \mathrm{cm}^{3}\right)\end{array}$ & $\begin{array}{l}\text { Average anion } \\
\text { concentration } \\
\left(\text { anions } / \mathrm{cm}^{3}\right) \\
\end{array}$ & $\begin{array}{c}\text { Temperature } \\
\left({ }^{\circ} \mathrm{C}\right)\end{array}$ & $\begin{array}{c}\text { Relative } \\
\text { humidity }(\%)\end{array}$ \\
\hline \multirow{2}{*}{ Laboratory } & Sample 1 & -1190 & -950 & -1076 & \multirow{2}{*}{20} & \multirow{2}{*}{50} \\
\hline & Sample 2 & -1150 & -800 & -968 & & \\
\hline \multirow{2}{*}{ Anion asphalt pavement } & Test point 1 & -7300 & -6300 & -5500 & \multirow{4}{*}{32.6} & \multirow{4}{*}{55} \\
\hline & Test point 2 & -3910 & -2700 & -2860 & & \\
\hline \multirow{2}{*}{ Common asphalt pavement } & Test point 1 & -180 & -60 & -120 & & \\
\hline & Test point 2 & -150 & -70 & -110 & & \\
\hline
\end{tabular}


In the same test situation, anion concentration released from road asphalt with the admixed anion additive is six times greater than that for road without admixed anion additive. The road asphalt containing admixed anion additive has shown excellent performance in the anion release test.

(2) Test summary. Natural anion asphalt pavement has an excellent anion release capacity, higher than that expected from the results measured in the laboratory. Without sunlight, natural anion asphalt pavement could release 3000 anions $/ \mathrm{cm}^{3}$; with sunlight, the number of anions released could reach 5000-6000 anions $/ \mathrm{cm}^{3}$. The number of anions released from natural anion asphalt pavement anion is significantly higher than that from ordinary asphalt pavement. Appropriate air humidity and adequate sunlight is conducive to improve the anion release from natural anion asphalt pavement.

\section{Conclusions}

This new technology allows a high percentage of modified recycled material to be incorporated (1:1), which is important for eradication of black pollution; and the large admixture of waste tire rubber powder reduced the wax content of domestic asphalt lower than the level of imported ones which in turn greatly improved the quality of domestic asphalt products. Using the patented technology in modified asphalt, so that the road surface can release anions during use, effectively improves the environment surrounding the road $[14,15]$.

This work was supported by the National "Eleventh Five-Year" Technology Support Program Foundation (2006BAD10B08) and the Natural Science Foundation of Hebei Province (E2009000448).

1 Liu J Y, Qiao Q, Chang L, et al. Service life of tire and amount of waste tire forecast in China. Chin Resour Compr Util, 2011, 29: 34-37

2 Aleksandrova S L, Kartashevskii A I, Tirakyan V E. Compatibility of rubbers with asphalt components and properties of artificial compounded asphalts. Chem Tech Fuels Oil, 1981, 17: 419-422

3 Estevez M. Use of coupling agents to stabilize asphalt-rubber-gravel composite to improve its mechanical properties. J Clean Prod, 2009, 17: 1359-1362

4 Liu X Y, Ma H Y, Miao S, et al. Self-assembled monolayers of stearic imidazoline on copper electrodes detected using electrochemical measurements, XPS, molecular simulation and FTIR. Chin Sci Bull, 2009, 54: 374-381

5 Wang R, Zhou J, Qiu X G. Intrinsic abnormal electromagnetic medium based on polar lattice vibration. Chin Sci Bull, 2011, 56: 13181324

6 Highway Asphalt Pavement Construction Technical Standard, JTGF402004 (in Chinese). Beijing: China Communications Press, 2004

7 The Test Criterion for Highway Project Pitch and Pitch Compounds, JTJ052-2000 (in Chinese). Beijing: China Communications Press, 2000

8 Wang X D. Guide for Design and Construction of Asphalt Rubber and Mixture (in Chinese). Beijing: China Communications Press, 2008

9 Pasquini E, Canestrari F, Cardone F, et al. Performance evaluation of gap graded asphalt rubber mixtures. Constr Build Mater, 2011, 25: 2014-2022

10 Fontes L P T L, Trichês G, Pais J C, et al. Pereira, Evaluating permanent deformation in asphalt rubber mixtures. Constr Build Mater, 2010, 24: 1193-1200

11 Partl M N, Pasquini E F, Canestrari A V. Analysis of water and thermal sensitivity of open graded asphalt rubber mixtures. Constr Build Mater, 2010, 24: 283-291

12 Akisetty C, Xiao F P, Gandhi T, et al. Estimating correlations between rheological and engineering properties of rubberized asphalt concrete mixtures containing warm mix asphalt additive. Constr Build Mater, 2011, 25: 950-956

13 Yeh J T, Hsiung H H, Wei W, et al. Negative air ion releasing properties of tourmaline/bamboo charcoal compounds containing ethylene propylene diene terpolymer/polypropylene composites. J Appl Polym Sci, 2009, 113: 1097-1110

14 Wang X M, Li Q S, Qi S T, et al. The release anion polymer natural asphalt composites (in Chinese). China Patent CN102199358A, 2011-09-28

15 Li B F, Li Q S, Wang X M. The asphalt concrete pavement materials of release anions (in Chinese). China Patent CN102199017A, 201109-28

Open Access This article is distributed under the terms of the Creative Commons Attribution License which permits any use, distribution, and reproduction in any medium, provided the original author(s) and source are credited. 